\title{
Bioactive compounds and medicinal properties of Aloe vera L.: An update
}

\author{
Bawankar Raksha, Singh Pooja, Subramanian Babu \\ School of Bio Sciences and Technology, VIT University, Vellore 632014, India
}

Email address:

rakbawankar@gmail.com (B. Raksha),mspooja06@gmail.com (S. Pooja), babu.s@vit.ac.in (S. Babu)

To cite this article:

Bawankar Raksha, Singh Pooja, Subramanian Babu. Bioactive Compounds and Medicinal Properties of Aloe Vera L.: An Update. Journal of Plant Sciences. Vol. 2, No. 3, 2014, pp. 102-107. doi: 10.11648/j.jps.20140203.11

\begin{abstract}
The practice of using Aloe vera extract as a herbal medicine basically depend on folklore and by experiences of people over a long period of time. Extensive research, especially in the area of basic biochemical characterization and elucidation of bioactivities has been conducted in a systematic manner. This has resulted in the characterization of many biochemical compounds from Aloe vera, predominantly using the techniques of spectroscopy and chromatography. Many biochemical compounds have been characterized from the Aloe vera using spectroscopy and chromatography techniques. Today, In addition to the well documented wound healing properties of Aloe vera extracts in burns, the antioxidant, antimicrobial and antidiabetic activities were tapped and hence formed the central core of bioactivity research on this plant in recent years. There have been preliminary reports on immune modulatory and other functions. The biochemical compounds and their bioactivity mechanisms from Aloe extracts, compounded by the bottlenecks in large scale cultivation represents a fascinating challenge to near complete exploitation and improvements in this pharmacologically important medicinal plant. This review is an effort to update our current knowledge on this plant based on many recent findings and to review the status for further exploration in pharmacology.
\end{abstract}

Keywords: Aloe Vera, Bioactive Compounds, Medicinal, Pharmacology, Plant

\section{Introduction}

All over the globe, many plants have been exploited for their medicinal value, Mukherjee and Wahile [1] reported about the considered opinion of World Health Organization, which states that, ' $80 \%$ of the world's population dependent on ancestral medicines for their haleness'. For the health care of the remaining $20 \%$ population mainly residing in developed countries, therapeutic product of plants plays an important role. Still there is a requisite for the development of scientific technology for the enhancement of medicinal plants and their products. For the isolation of lead compounds, assorted classes of plant species have been analysed with the help of upgraded Ayurvedic traditional methods and other advanced scientific exploration. Innumerable therapeutic agents can be obtained from medicinal plants after screening of secondary metabolite compounds [2].

Of the medicinal plants, Aloes have been used for therapeutic purposes since ancient times. Common names of the plant include Aloe, Aloe capensis, Aloe spicata, Aloe vera, Barbados loe, Cape aloe, Chirukattali (India),
Curacao aloe, Ghai Kunwar (India), Ghikumar (India), Indian aloes, Kumari (Sanskrit), Laloi (Haiti), Lohoi (Vietnam), Luhui (Chinese), Nohwa (Korean), Rokai (Japanese), Sabilla (Cuba), Socotrine aloe, Subr (Arabic), Zanzibar aloe .

There is a great variegation of therapeutically eloquent substances produced by Aloe vera which have eminent significance in many areas of medicine. An entirety of 75 compounds is present in the leaf of Aloe, and each one has a variety of remedial properties. These include lignin (capacity of penetrating the human skin), saponins (antiseptic property as well as foaming agent), anthraquinones (aloin, isobarbaloin, anthracene, emodin, ester of cinnamoic acid, chrysophanic acid, barbaloin, anthranol, aloectic acid, aloe emodin and ethereal oil), minerals (calcium, manganese, sodium, copper, magnesium, potassium, zinc, chromium and iron), vitamins (Vit A, C, E, $\mathrm{B}_{12}$ and Choline), amino acids ( 20 of 22 required amino acids and seven of eight essential ones), enzymes (peroxidase, aliiase, catalase, lipase, cellulase, carbxypeptidase, amylase and alkaline phosphatase) and sugars (monosaccharides and polysaccharides). However, 
like in other medicinal plants, it remains a mystery whether the bioactivities exhibited by the plant extract are due to single compound or the consequence of synergistic effect of many compounds. It is not only important to know constituents of Aloe vera extracts but also the relative importance in their therapeutic value [3]. In this review, we discuss the biochemical characterization and reports on bioactive potentials of this important medicinal plant.

\section{Botanical Description}

Aloe vera (synonym: Aloe barbadencis Miller) belong to Liliaceae family. It is a stemless or very short-stemmed succulent plant which grows to $60-100 \mathrm{~cm}$ (24-39 in) tall, spreads by offsets, and its leaves are very thick and fleshy with the profound colour of green to grey-green. Some of its varieties show white flecks on the upper and lower stem surfaces. The leaf has serrated margin with small white teeth. The perimetric bundle sheath cells give rise to bitter, yellow exudates. During the season of summer flowers are blossomed on a spike up to $90 \mathrm{~cm}$ (35 in) in height and each flower is pendulous with a yellow tubular corolla 2 to $3 \mathrm{~cm}$ ( 0.8 to 1.2 in) long. On the outward region of the rosette most mature leaves are present [4].

\section{Cultivation and Propagation}

There is a lack of production of Aloe leaf to meet the industry demand as reported by Aggarwal and Barna [5]. Natural propagation of Aloe vera is primarily by means of axillary shoots and it is rather a slow way of multiplication to meet the growing demand. The presence of male sterility among Aloe species is also a barrier in rapid propagation [6]. In vitro technique offers a possibility to solve these problems. There have been several attempts to cultivate Aloe vera under in vitro conditions using stem node, shoot tips and microshoots was analysed $[7,8]$. However, being a perennial plant and a slow grower, optimization of tissue culture techniques and hardening in soil have a long way to go before a portion of mass cultivation of Aloe vera can depend on in vitro propagation.

\section{Biochemical Characterization}

Aloe vera leaf has been alienated in two major parts namely the external green rind including the vascular bundles and the internal colorless parenchyma containing the aloe gel. Nearly $98.5 \%$ of water content is present in the raw pulp of Aloe vera, while 99.5 percentile was shown in the mucilage or gel. It has the $\mathrm{pH}$ of 4.5 . The residual solid material approximately 0.5 to $1 \%$ consists of a range of compounds which include vitamins which are water-soluble and fat soluble, minerals, enzymes, polysaccharides, phenolic compounds and organic acids as reported by Hamman [9] and Boudreau and Beland [10]. Chemical composition of Aloe vera leaf pulp and exudates were reported [11] and is summarized in Table 1.
Arunkumar and Muthuselvam [12] performed the screening for phytochemical compounds, a positive result was obtained for tannin, saponin, flavonoids and terpenoids but tests for steroids gave negative results. We have recently identified 26 bioactive phytochemical compounds in the ethanolic extract of Aloe vera [13] and found that hexadecanoic acid (22.2\%) was the major compound followed by octadecanoic acid (16.2\%), tricosane $(5.59 \%)$ and 1-octadecanol (5.20\%). Sitosterol and Stigmasterol are present in amount of 2.8 and $2.1 \%$ respectively. HPLC analysis confirmed the presence of stigmasterol of about $2.09 \%$.

Saleem et al. [14] reported a new compound i.e. 3, 4-dihydro-3, 5, 7-trihydroxy-9-methyl-(2H)- anthracenone from the roots of Aloe barbadensis and was nominated as aloe barbendol. An evaluation of quality and authenticity of commercially available Aloe vera gel powder was performed by nuclear magnetic resonance spectrometry (NMR) and nine products were obtained which then compared with fresh Aloe vera gel. The amount of mannose after acid hydrolysis gave a measurement in the rapid way as well as in a direct way for the concentration of polysaccharide -acemannan and was found to be present in satisfactory amounts $(10 \% \mathrm{w} / \mathrm{w})$.

\section{Bioactivity and Pharmacological Properties}

\subsection{Antioxidant Activity}

Plant-derived antioxidants for example phenolics, are known to be an imperative components due to their prospective beneficial possessions. Arabshahi- Delouee and Urooj [15] reported that for the reduction of cancer and cardio-vascular diseases, consumption of antioxidant rich plant food is constructive for good health. Effectively Aloe vera possesses many pharmacological activities including an ti-inflammatory [16] and antitumour [17] with the involvement of the mediation of ROS level. Some antioxidant components are present naturally in the aqueous extract of Aloe vera leaves which includes total phenols, flavonoids, ascorbic acid, $\beta$-carotene and $\alpha$ - tocopherol [18]. Nwanjo [19] performed the treatment of diabetic rats with the aid of leaves of Aloe barbadensis (150 $\mathrm{mg} \mathrm{kg}^{-1}$ ) which increases the antioxidant enzymes like SOD activities, and significantly reduced the lipid peroxidation products and they concluded that augmented blood sugar leads to amplified oxidative stress and it was found that extract of Aloe barbadensis leaves possesses good antioxidant activities. Sultana et al. [20] checked for antioxidant activity of Aloe barbadensis leaf extracts obtained using four extracting solvents and two unique extraction techniques. They reported that the extracts had a good DPPH scavenging property. It has also been proved [21] that in the occurrence of copper ions in the aqueous extract of Aloe vera the DNA is degraded and there is a reduction of $\mathrm{Cu}$ (II) to $\mathrm{Cu}$ (I) along with generation of reactive oxygen species such as 
superoxide anion and hydroxyl radicals in a dose dependant manner. This observation demonstrates the pro-oxidant property in addition to its antioxidant property.

Anilkumar et al. [22] suggested that gel extract of Aloe vera confirms the property of reduction of AOM-induced oxidative stress and the presence of noxious in liver. Rajasekaran et al. [23] observed an increase in the hemoglobin and the reduction in the level of blood glucose and glycosylated haemoglobin. It was also seen that there is a noteworthy rise in reduced glutathione, superoxide dismutase, catalase, glutathione peroxidase and
glutathione-S-transferase in the liver and kidney of the treated rat. Esteban et al. [24] has analysed the basic peroxidase in the commercially available aloe gel as well as in the Aloe vera plant and it has been found to occur in the vascular system of the internal aqueous leaf parenchyma. It was concluded that peroxidase enzyme in skin surface possibly can scavenge $\mathrm{H}_{2} \mathrm{O}_{2}$. This illuminates that the Aloe vera plant has been constituted with agreeable antioxidant properties, and moreover this can serve as an evidence for taking this plant based products further to the treatment of numerous neurological disorders.

Table 1. Chemical composition of Aloe vera

\begin{tabular}{|c|c|c|}
\hline S.No. & Compound & Type of compound \\
\hline 1. & Anthraquinone & $\begin{array}{l}\text { Aloe-emodin, aloectic acid, anthranol, aloin A and B (or collectively known as barbaloin), isobarbaloin, } \\
\text { emodin and ester of cinnamic acid }\end{array}$ \\
\hline 2. & Carbohydrate & $\begin{array}{l}\text { Pure mannan, acetylated mannan, acetylated glucomannan, glucogalactomannan, galatan, } \\
\text { galactogalacturan, arabinogalactan, galactoglucoarabinomannan, pectic substance, xylan, cellulose, } \\
\text { chromones, isoaloeresin-D, isoarabaichromone and neoaloesin A. }\end{array}$ \\
\hline 3. & Enzymes & $\begin{array}{l}\text { Phosphatase, amylase, carboxypeptidase, catalase, cyclooxidase, cyclooxigenase, lipase, oxidase, } \\
\text { phosphoenolpyruvate carboxylase and superoxide dismutase. }\end{array}$ \\
\hline 4. & Inorganic compounds & $\begin{array}{l}\text { Calcium, chlorine, chromium, copper, iron, magnesium, manganese, potassium, phosphorous, sodium } \\
\text { and zinc. }\end{array}$ \\
\hline 5. & $\begin{array}{l}\text { Organic compounds and } \\
\text { lipids }\end{array}$ & $\begin{array}{l}\text { Arachidonic acid,- linolenic acid, triglycerides, triterpenoid, gibberellins, lignin, potassium sorbate, } \\
\text { salicylic acid and uric acid. }\end{array}$ \\
\hline 6. & $\begin{array}{l}\text { Non essential and essential } \\
\text { amino acids }\end{array}$ & $\begin{array}{l}\text { Hydroxyproline, isoleucine, leucine, lysine, methionine, phenylalanine, praline, threonine, tyrosine and } \\
\text { valine }\end{array}$ \\
\hline 7. & Proteins & Lectins and lectin-like substance \\
\hline 8. & Saccharides & Mannose, glucose, $L$-rhamnose and aldopentose \\
\hline 9. & Vitamins & $\mathrm{B}_{1}, \mathrm{~B}_{2}, \mathrm{~B}_{6}, \mathrm{C}, \beta$-carotene, choline, folic acid, $\beta$-carotene, choline, folic acid, $\alpha$-tocopherol \\
\hline 10. & Sterols & Campesterol, cholesterol and $\beta$-sitosterol \\
\hline
\end{tabular}

\subsection{Antidiabetic Effects}

The last two decades have seen varied reports providing evidence for the therapeutic property of Aloe vera to heal diabetes. Agarwal [25] was the first to give report on diabetic patients, following this report there are several reports on diabetic patients. Rajasekaran et al. [26] and Kim et al. [27] analysed the effect of Aloe vera against diabetes with the aid of in streptozotocin induced diabetic animal models and non-insulin dependent diabetes mellitus. Tanaka et al. [28] identified five phytosterols of Aloe vera which have the property to act against diabetes and reported its consequence on hyperglycemia and hyperlipedemia using animal studies. Nomaguchi et al. [29] proved that the phytosterols act as ligands for peroxisome proliferator activated receptors and they showed that it has an enhanced expression of the target genes at the liver of the diet-induced obesity test mice.

\subsection{Inhibitory Activity against Microorganisms}

Numerous studies have elucidated the antagonistic activity of Aloe vera against fungi, virus and bacteria and it was screened against selected clinical pathogens by agar diffusion method using aqueous, ethanol and acetone extract of Aloe vera and showed that paramount enmity activity against bacteria and fungus was present in acetone extract $[24,30,32]$. The growth of Helicobacter pylori is hindered by the Aloe vera in a dose-dependent manner [31]. The sterol extract showed higher activity against Streptomyces.greseus and Candida albicans as compared to other bacteria and fungi when screened for antibacterial and antifungal activities respectively [13]. Dried latex (Aloe drug) and extractives of Aloe vera obtained by hexane, ethyl acetate and methanol were tested to assess their activity against some pathogenic fungi, and to understand the chemical nature of the active principles present in them. It was found that the extractives showed higher inhibitory activity against Colletotrichum species than as compared to Fusarium solani. Two constituents, namely aloin and aloe-emodin were identified as active principles by their activity against Colletotrichum gloeosporides and Cladosporium cucumerinum [32]. On the other hand, Saks and Barkai-Golan [30] have observed regarding an inhibitory potential of Aloe vera gel against fungi like Penicillium digitatum, P. expansum, Botrytis cineria, and Alternaria alternate at different concentrations. The inhibitory property of Aloe vera towards the growth of bacteria and fungi can prove to be an additional asset in the therapeutic role that the plant plays in the current pharmaceutical industry.

\subsection{Immunomodulatory Effects}

Another potential characteristic of immunomodulatory activity of Aloe vera was exhibited in various animal models [33]. Reynolds and Dweck [34] reported that polysaccharides of the inner gel of Aloe vera have a varied 
immunomodulatory activity. Akhtar et al. [16] has reported immunostimulatory and protective effects of Aloe vera against coccidiosis in industrial broiler chickens.

\subsection{Wound Healing}

One of the well known property of Aloe vera gel is wound healing ability. It accelerates many internal and external wound healing processes like peptic ulcer, dermal and subdermal tissues. A highly efficient cream preparation was reported [35]. Postoperative peritoneal adhesions which are causes for intestinal obstruction, infertility and abdominal and pelvic pains have no effective solutions other than treatment with Aloe vera. Its gel can effectively decrease adhesion formation and prevent peritoneal trauma probably due to the viscosity of the gel but not due to its chemical properties [36].

\section{Other Beneficial Properties}

Another beneficial property of Aloe vera is chemopreventive activity against tumor enlargement and it has been proved with the help of an animal model [37]. Evidences for hepatoprotective components in Aloe vera are reported based on a study on mice [38]. A systematic review was published in 2005 on the therapeutic evidences of Aloe vera in radiation induced skin reactions [39]. Langmead et al. [40] reported that oral consumption of Aloe vera is a good practice for the reduction of symptoms and the inflammation in patients with ulcerative colitis. Habeeb et al. [41] found that Aloe vera can be beneficial to treat genital herpes and psoriasis. Pathogenic Salmonella and Shigella induced inflammations are also found to be suppressed by Aloe vera. In addition, it is also helpful in healing insect bites, rashes, vaginal infections, conjunctivitis and allergic reactions, which have been described by Vogler and Ernst [42].

\section{Conclusions and Future Prospects}

In last decade, there is a renewed interest in the development of herbal drugs which has underlined understanding the mechanism of action rather than blind faith in people and stories, as in the past. Several approaches in exploiting the herbal wealth of the world in phytomedicine have explored many phytochemicals from variety of plants. Nonetheless, even with the limited reports on mechanism of activity it has become obvious that numerous mechanisms would have been involved in different activities of a given herbal medicine.

From the historical era it has been proved that Aloe vera is the sturdy candidate for exploitation as a potential pharmaceutical agent. Aloe gel has been very well known for its use in cosmetics as well as in the other areas of medicine such as its property to heal cancer and treat AIDS. In traditional medicine use of plants shows presence of their therapeutic compounds. In such perspective, testing the biological activity of Aloe vera and related plants demands a special approach. To find suitable drug candidates from Aloe vera, plethora of experimental procedures are available. A screening tool box with two indices index 1-screening plant extracts, active ingredients and pure compounds, index 2-drug properties, pharmacological and pharmacokinetic properties are developed. This would speed up as well as help to choose appropriate screening models.

Further research is an immediate requirement for considering bioactivity of the compounds as well as isolating their purified forms. There is a great opportunity for the cultivation of Aloe vera which shows highly economic importance but still there is lack of information about its cultivation and management. There are only very few reports including the recent water use efficiency study and biomass production in this plant. In additions, the bioactivities already proved in animal studies should be taken forward to the clinical trials in human. This is because with all the positive effects reported, Aloe vera could be a medicine for many of the ailments for which no cure is available.

\section{References}

[1] Mukherjee, P.K. and Wahile, A. Integrated approaches towards drug development from Ayurveda and other Indian system of medicines. Journal of Ethanopharmacology 103: $5-35,2006$

[2] Trivedi, P., Shinde, S. and Sharma, C. Preliminary phytochemical and pharmacological studies on ficus racemosa. Indian Journal of Medical Research 57: 1070-1074, 1969.

[3] Surjushe, A., Vasani, R. and Saple, D.G. Aloe vera : A short review. Indian Journal of Dermatology 4: 163-166, 2008.

[4] Sampathkumar, K.P., Bhowmik, D. and Chiranjib, B. Aloe vera: A potential herb and its medicinal importance. Journal of Chemical and Pharmaceutical Research 2: 21-29, 2010.

[5] Aggarwal, D. and Barna, K.S. Tissue culture propagation of elite plant of Aloe vera Linn, Journal of Plant Biochemistry and Biotechnology 13: 77-79, 2004.

[6] Natali, L., Sanchez, I.C. and Cavallini, A. In vitro culture of Aloe barbadensis Mill Micropropagation from vegetative meristems. Plant Cell Tissue and Organ Culture 20: 71-74, 1990.

[7] Hashemabadi, D. and Kaviani, B. Rapid micro-propagation of Aloe vera L. via shoot multiplication. African Journal of Biotechnology 7: 1899-1902, 2008.

[8] Hashemabadi, D. and Kaviani, B. In vitro proliferation of an important medicinal plant Aloe-A method for rapid production. Australian Journal of Crop Science 4: 216-222, 2010 .

[9] Hamman, J.H. Composition and applications of Aloe vera leaf gel. Molecules 13: 1599-1616, 2008.

[10] Boudreau, M.D. and Beland, F.A. An evaluation of the biological and toxicological properties of Aloe barbadensis (Miller). Journal of Environmental Science and Health 24: 103-154, 2006. 
[11] Femenia, A., Sanchez, E.S., Simal, S. and Rosello, C. Compositional features of polysaccharides from Aloe vera (Aloe barbadensis Miller) plant tissues. Carbohydrate Polymers 39: 109-117, 1999.

[12] Arunkumar, S. and Muthuselvam, M. Analysis of phytochemical constituents and antimicrobial activities of Aloe vera L. against clinical pathogens. World Journal of Agricultural Sciences 5: 572-576, 2009.

[13] Bawankar, R., Deepti, V.C., Singh, P., Subashkumar, R., Vivekanandan, G. and Babu, S. Evaluation of bioactive potential of an Aloe vera sterol extract. Phytotherapy Research 27: 864-868, 2013.

[14] Saleem, R., Faizi, S., Deeba, F., Siddiqui, S. and Qazi, M.H. Anthrones from Aloe barbadensis. Phytochemistry 456: 1279-1282, 1996.

[15] Arabshahi-Delouee, S. and Urooj, A. Antioxidant properties of various solvent extracts of mulberry (Morus indica L.) leaves. Food Chemistry 102: 1233-1240, 2007.

[16] Akhtar, M., Hai, A., Awais, M.M., Iqbal, Z., Muhammad, F., Ul Haq, A. and Anwar, M.I. Immunostimulatory and protective effects of Aloe vera against coccidiosis in industrial broiler chickens. Veterinary Parasitology 186: 170-177, 2012.

[17] Corsi, N.M., Berelli, A.A., Gaja, G., Fulgenzi, A. and Ferrero, M.E. The therapeutic potential of Aloe vera in tumour bearing rats. International Journal of Tissue Reactions 20: $115-118,1998$

[18] Ozsoy, N., Canadoken, E. and Akev, N. Implications for degenerative disorders. Oxidative Medicine and Cellular Longevity 2: 99-106, 2009.

[19] Nwanjo, H.U. Antioxidant activity of the exudates from Aloe barbadensis leaves in diabetic rats. Biochemistry 18: 77-81, 2006.

[20] Sultana, B., Anwar, F. and Ashraf, M. Effect of extraction solvent/technique on the antioxidant activity of selected medicinal plant extracts. Molecules 14: 2167-2180, 2009.

[21] Naqvi, S., Ullah, M.F. and Hadi, M.S. DNA degradation by aqueous extract of Aloe vera in the presence of copper ions. Indian Journal of Biochemistry and Biophysics 47: 161-165, 2010 .

[22] Anilkumar, K.R., Sudarshankrishna, K.R., Chandramohan, G., Ilaiyaraja, N., Khanum, F. and Bawa, A.S. Effect of Aloe vera gel extract on antioxidant enzymes and azoxymethane induced oxidative stress in rats. Indian Journal of Experimental Biology 48: 837-842, 2010.

[23] Rajasekaran, S., Sivagnanam, K., Ravi, K. and Subramanian, S. Hypoglycemic effect of Aloe vera gel on streptozotocin-induced diabetes in experimental rats. Journal of Medicinal Food 7: 61-66, 2004.

[24] Esteban, A., Zapata, J.M., Casano, L., Martin, M. and Sabater, B. Peroxidase activity in Aloe barbadensis commercial gel: Probable role in skin protection. Planta Medica 66: 724-727, 2000.

[25] Agarwal, O.P. Prevention of atheromatous heart disease. Angiology 36: 485-492, 1985
[26] Rajasekaran, S., Ravi, K., Sivagnanam, K. and Subramanian, S. Beneficial effects of Aloe vera leaf gel extract on lipid profile status in rats with streptozotocin diabetes. Clinical and Experimental Pharmacology and Physiology 33: 232-237, 2006.

[27] Kim, K., Kim, H., Kwon, J., Lee, S., Kong, H., Im, S-A., Lee, Y.H., Lee, Y.R., Oh, S.T., Jo, T.H., Park, Y.I., Lee, C.K. and Kim, K. Hypoglycemic and hypolipidemic effects of processed Aloe vera gel in a mouse model of non-insulin-dependent diabetes mellitus. Phytomedicine 16: 856-863, 2009.

[28] Tanaka, M., Misawa, E., Ito, Y., Habara, N., Nomaguchi, K., Yamada, M., Toida, T., Hayasawa, H., Takase, M., Inagaki, M. and Higuchi, R. Identification of five phytosterols from Aloe vera gel as anti-diabetic compounds. Biological and Pharmaceutical Bulletin 29: 1418-1422, 2006.

[29] Nomaguchi, K., Tanaka, M., Misawa, E., Yamada, M., Toida, T., Iwatsuki, K., Goto, T. and Kawada, T. Aloe vera phytosterols act as ligands for PPAR and improve the expression levels of PPAR target genes in the livers of mice with diet-induced obesity. Obesity Research and Clinical Practice 5: 190-201, 2011.

[30] Saks, Y. and Barkai-Golan, R. Aloe vera activity against plant pathogenic fungi. Postharvest Biology and Technology 6: 159-165, 1995.

[31] Wang, H., Chung, J., Ho, C., Wu, L. and Chang, S. Aloe-emodin effects on arylamin $\mathrm{N}$-acetyltransferase activity in the bacterium Helicobacter pylori. Planta Medica 64: 176-178, 1998.

[32] Sebastian, N.E., Ganeshan, J. and Lokesha, A.N. Antifungal activity of some extraction and constituents of Aloe vera. Research Journal of Medicinal Plant 5: 196-200, 2010.

[33] Talmadge, J., Chavez, J., Jacobs, L., Munger, C., Chinnah, T., Chow, J.T., Williamson, D. and Yates, K. Fractionation of Aloe vera inner gel, purification and molecular profiling of activity. International Immunopharmacology 4: 1757-1773, 2004.

[34] Reynolds, T. and Dweck, A.C. Aloe vera leaf gel: a review update. Journal of Ethnopharmacology 68: 3-37, 1999.

[35] Bunyapraphatsara, N., Yongchaiyudha, S., Rungpitarangsi, V. and Chokechaijaroenporn, O. Anti-diabetic activity of Aloe vera $\mathrm{L}$. juice. II. Clinical trial in diabetes mellitus patients in combination with glibenclamide. Phytomedicine 3: 245-248, 1996.

[36] Aysan, E., Bektas, H. and Ersoz, F. A new approach to postoperative peritoneal adhesions: prevention of peritoneal trauma by Aloe vera gel. European Journal of Obstetrics, Gynecology and Reproductive Biology 149: 195-198, 2010.

[37] Akev, N., Turkay, G., Can, A., Gurel, A., Yildiz, F., Yarbidi, H.H., Ekiz, E.E. and Uzun, H. Effect of Aloe vera leaf pulp extract on Ehrlich ascites tumours in mice. European Journal of Cancer Prevention 16: 151-157, 2007.

[38] Gbadegesin, M.A., Odunola, O.A., Akinwumi, K.A. and Osifeso, O.O. Comparative hepatotoxicity and clastogenicity of sodium arsenite and three petroleum products in experimental Swiss Albino Mice: The modulatory effects of Aloe vera gel. Food and Chemical Toxicology 47: 2454-2457, 2009. 
[39] Richardson, J., Smith, J.E., Mcintyre, M., Thomas, R. and Pilkington, K. Aloe vera for preventing radiation-induced skin reactions: A systemic literature review. Journal of Clinical Oncology 17: 478-484, 2005.

[40] Langmead, L., Feakins, R.M., Goldthorpe, S., Holt, H., Tsironi, E., De Silva, A., Jewell, D.P. and Rampton, D.S. Randomized double-blind, placebo-controlled trial of oral Aloe vera gel for active ulcerative colitis. Alimentary Pharmacology and Therapeutics 19: 739-747, 2004.
[41] Habeeb, F., Shakir, E., Bradbury, F., Cameron, P., Taravati, M.R., Drummond, A.J., Gray, A.I. and Ferro, V.A. Screening methods used to determine the anti-microbial properties of Aloe vera inner gel. Methods 42: 315-320, 2007.

[42] Vogler, B.K. and Ernst, E. Aloe vera: a systematic review of its clinical effectiveness. British Journal of General Practice 49: 823-828, 1999. 